\title{
Contra a estupidez calculista da tecnocultura ocidental
}

\author{
Against the calculist stupidity of Western technoculture
}

\section{Guilherme Kujawski}

É produtor de conteúdo, curador e autor de ficção científica. Mestre em Artes Visuais pela Donau-Universität Krems, Áustria, e Doutor em Ciências pelo Instituto de Arquitetura e Urbanismo da Universidade de São Paulo. Atualmente é coordenador do curso Arte e Mídias Digitais na Escola Britânica de Artes Criativas, em São Paulo.

Submetido em 18 de Agosto de 2020 Aceito em 24 de Setembro de 2020

\section{RESUMO}

A última obra do filósofo chines Yuk Hui esboça, em alusão à pensadores de diversas épocas, um programa para se pensar o papel da tecnologia na sociedade contemporânea. Para tanto, o autor examina o fenômeno da recursão, processo evolutivo fundado na autorreflexão de sistemas, e o da contingência, eventos imprevistos aos quais aqueles se sujeitam. É uma crítica ao atual modo de produção de conhecimento, hegemonicamente refém da computação em escala planetária. Em contraste, Hui propõe a unificação da ordem cósmica e a diversidade técnica, reorganizando elementos extraídos tanto da cibernética como da ecologia.

PALAVRAS-CHAVE: Filosofia da tecnologia; cosmologia; metafísica; ciência da computação; ecologia.

\section{ABSTRACT}

The last work of the chinese philosopher Yuk Hui outlines, in allusion to thinkers from different eras, a program to think about the role of technology in contemporary society. Therefore, the author examines the phenomenon of recursion, an evolutionary process based on self-reflection of systems, and of contingency, unforeseen events to which those are subjected. It is a critique of the current mode of knowledge production, hegemonically hostage to planetary-scale computing. In contrast, Hui proposes the unification of the cosmic order and technical diversity,

Dossiê 0 Pensamento Ecológico - https://revistaecopos.eco.ufrj.br/

ISSN $2175-8689$ - v. 23, n. 2, 2020

DOI: 10.29146/eco-pos.v23i2.27578 
reorganizing elements extracted from both cybernetics and ecology.

KEYWORDS: Philosophy of technology; cosmology; metaphysics; computer science; ecology.

\section{RESUMEN}

La última obra del filósofo chino Yuk Hui esboza, aludiendo a pensadores de varias épocas, un programa de reflexión sobre el papel de la tecnología en la sociedad contemporánea. Por lo tanto, el autor examina el fenómeno de la recursividad, un proceso evolutivo basado en la autorreflexión de los sistemas, y el de la contingencia, los imprevistos a los que están sometidos. Es una crítica al actual modo de producción de conocimiento, hegemónicamente rehén de la computación a escala planetaria. En cambio, Hui propone la unificación del orden cósmico y la diversidad técnica, reorganizando elementos extraídos tanto de la cibernética como de la ecología.

Pallabras-clave: Filosofía de la tecnología; cosmología; metafísica; Ciencia de la computación; ecología.

Em seu último livro, Yuk Hui avalia sob nova perspectiva a cibernética e a ecologia, bem como desvenda as intrincadas relações entre o pensamento mecanicista (desde Descartes) e o organicista (desde Kant), personificado como a sua antítese. É adicionado aos dois termos um terceiro, a visão de mundo vitalista, versão atualizada da enteléquia aristotélica e guia de diversas correntes da fisiologia clássica, insatisfeitas com o reducionismo da máquina como metáfora de todas as coisas. 0 leitor conclui, ao final, que, de fato, não há como reduzir as complexas articulações entre partes e todo como um mero debate sobre as conexões entre a totalidade, as partes prevalentes que a compõem e um "excedente" vital, invocado em casos de inconsistência da relação parte-todo. Para além das recorrentes controvérsias, mecanicismo, organicismo e vitalismo puseram-se a alinhar, seja em pares ou em trincas, ao longo da história da ciência e do pensamento. Por exemplo, comparado ao mecanicismo do médico e filósofo iluminista Julien de la Mettrie para quem até os processos cerebrais podiam ser descritos por princípios físicos, 
posição ousada para a doutrina cristã da época -, o restrito modelo mecanicista de Descartes, quando aplicado às funções fisiológicas não precípuas da bête machine, havia de recorrer, mesmo que inadvertidamente, ao antagônico princípio vitalista (Burnham, 1968, p. 59).

A jornada noética de Hui inicia-se com uma análise acerca da organização sistêmica pousada no juízo reflexivo kantiano, de caráter não teórico, que, em termos gerais, busca identificar o universal em particulares. A reflexividade, mais precisamente o juízo teleológico, para Hui, é a pedra basilar da recursividade, palavra familiar entre os cientistas da computação, mas que descreve a evolução utilitária, iterativa e não repetitiva de qualquer sistema. A teleologia insinua-se na Naturphilosophie do século 19 à guisa de condicional finalista: como se as coisas da natureza determinassem suas estratégias de desenvolvimento. Hui, após transmutar reflexividade em recursividade, perscruta o idealismo germânico pós-Kantiano (em especial, Schelling) para desconfrontar contingência e necessidade, examinando as diversas associações filosóficas entre natureza e alma, sendo a última uma sutil composição que tem a "habilidade de voltar a si mesma, a fim de se conhecer e se determinar", abrindo-se, em seu movimento espiralado, às "contingências que, por seu lado, determinam a sua singularidade" (Lovink, 2019).

A circularidade formada pela mente que percebe e a natureza percebida é a imagem perfeita da interação entre a parte e o todo, organismo e organicidade. Isto posto, deduz-se que a Naturphilosophie é ecologia em estado latente. Assim como é cibernética, disciplina que sistematiza as organizações em diversos níveis da realidade. Pode-se dizer que a filosofia da natureza de Schelling assenta um calço entre o mecanicismo reducionista e o vitalismo das forças misteriosas, forjando em seu lugar uma "terceira via" organicista, por certo ainda incipiente, mas já portando o "paradigma de um pensamento que move-se da ciência materialista para o materialismo orgânico" (Hui, 2019, p. 94). Por mais paradoxal que seja, nem toda a versão organicista rejeita o mecanismo, lembra Hui, sobretudo o mecanicismo orgânico de estudiosos de morfologia celular, os quais sentem-se à vontade para 
comparar a formação de estruturas celulares com a de cristais e outros processos de precipitação (Lenoir, 1982, p. 222). Depreende-se daí que certas acepções de organicismo emparelham sistemas mecânicos e biológicos, mas sempre em atenção à relação das partes com o todo. Pode-se também aludir nessa linhagem geólogos como James Hutton, que alcunhou o planeta Terra de "máquina viva", dando origem a analogias como a do vulcão e a máquina a vapor (Hui, 2019, p. 103).

Os conceitos de contingência e recursividade, continua Hui, estariam todo impregnados no trabalho de Hegel. Seria a sua fenomenologia, o movimento do espírito, o indício de um algoritmo? Tal operação seria disparada com a coleta inicial de dados do mundo externo, procedendo em seguida do abstrato ao concreto por meio de uma lógica reflexiva. Embora ambos tenham sido influenciados por Goethe, há uma diferença significativa entre Hegel e Schelling no que diz respeito ao papel do mundo natural como instância prospectiva: enquanto para o primeiro ele seria já de saída o objeto da reflexão, para o último ele deve antes de tudo ser pressentido e descoberto (Hui, 2019, p. 127). É certo que a teleologia espontânea verificada na natureza, para Hegel, só poderia apresentar-se como silogística, e para tanto ele toma como exemplo os três estágios de desenvolvimento das plantas: autorreconhecimento da semente como ser, o reconhecimento pela árvore jovem do outro (leia-se: o ambiente) e, finalmente, a determinação de uma unidade - um processo de individuação recursivo, analógico a tantos outros, mesmo o progresso do espírito. 0 que justifica tamanho malabarismo intelectual da lógica reflexiva hegeliana é, no enfrentamento entre natureza e razão, a "domesticação" da contingência irracional e o controle parcial de suas condições de possibilidade.

A identificação da recursividade como contingência necessária na obra de Hegel leva Hui a alegar uma conexão não causal, mas correlacional, entre a lógica reflexiva e a sistematização do processo recursivo pela cibernética, levando-o a questionar se a disciplina artífice da retroalimentação e da informação representaria a nova exigibilidade do ato filosófico. 0 próprio Heidegger, lembra Hui, proclamou algo similar na polêmica entrevista para a revista alemã Der Spiegel, a de 
que a missão da cibernética seria substituir a metafísica (Augstein \& Wolff, 1976). Além disso, o filósofo alemão não apenas entreviu que a principal característica da cibernética é transformar todas as operações orgânicas e mecânicas em procedimentos calculáveis; ele também a interpretou como sendo a vitória de um novo método científico, o qual integra a contingência em sistemas não projetados para lidar com "surpresas". Essa é a base a partir da qual se insere o pensamento algorítmico, fundado em recursão que, diferente da automação repetitiva, proporciona a capacidade de o programa de computador se postular e autorreferenciar-se. É essa forma circular do "reflexo-em-si" por via da "reflexãoem-outros" que leva ciberneticistas radicais como Gotthard Gunther a aventar a possibilidade de uma "consciência artificial".

A partir do terceiro capítulo, o organicismo, que oscila entre o biológico e o mecânico, dá lugar à organologia, termo procedente da musicologia e reapropriado por filósofos como Georges Canguilhem e Bernard Stiegler para estipular, em sua generalidade, a maneira de pensar a co-individuação de órgãos somáticos, organismos técnicos e organizações sociais. Hui oferece a sua própria versão organológica, chamada por ele de cosmotécnica, mas antes adverte sobre o engano recorrente de transformar a analogia entre organismo e mecanismo em uma equivalência, sugerindo que seria mais produtivo desenvolver uma estratégia de coexistência. Nesse sentido, se uma inteligência artificial vence o campeão mundial do jogo de tabuleiro Go, não seria o caso de celebrar, como o fazem os transumanistas, nem de lamentar, de acordo com o receituário humanista, mas de observar que a equivalência é apenas funcional, e não operacional, e que nada é decisivo na contínua interação humano-computador. Na busca por sua definição de organologia, o olhar de Hui incide primeiro sobre a externalização, qual seja, a organização do inorgânico, como ferramentas (funções somáticas estendidas) e mídias (memórias estendidas). Numa primeira análise, o organismo engendra o mecanismo, dando a entender que o biológico seria anterior ao tecnológico, mas o que Stiegler procura descrever em sua organologia, mais voltada aos órgãos do que ao organismo, é que não haveria 
uma precedência, e sim uma concomitância no processo de hominização.

Será visto que uma organologia implícita permeia a teoria da individuação de Gilbert Simondon, se juntarmos no mesmo arcabouço a interação entre estrutura e operação (chamada por ele de alagmática), o estudo dos objetos técnicos e a noção de transindividuação. É possível, nesse sentido, questionar a autonomia da técnica, porque o processo recursivo da individuação é uma dinâmica recíproca entre as partes (humanos e máquinas) e holística em relação ao todo. Hui interpela nesse ponto sobre a possibilidade - ou não - de a automação substituir empregos humanos. Consideremos as atividades criativas, e não funcionais: uma rede contraditória generativa (GAN, na sigla em inglês) é uma tecnologia de aprendizado de máquina na qual duas redes neurais competem entre si em um jogo de imitação na elaboração, por exemplo, de projetos artísticos. Resumidamente, uma das redes faz o papel do "crítico", enquanto a outra se coloca como um "aprendiz" que busca imitar o mestre (na verdade, um enorme banco de imagens). 0 aprendiz é alçado a mestre quando o crítico não consegue mais discernir a produção "inovadora" de seus modelos. No mundo real, a diferença é que os aprendizes, após imitarem o mestre à perfeição, dão um "salto quântico" para um plano fora da mimese, criando um novo sistema de significação pessoal. É esse salto que as inteligências artificiais miméticas não conseguem executar; elas não logram desvincular a criatividade da inteligência.

A pergunta de Hui, a essa altura da obra, é: qual a relação entre tecnologia e natureza? Ela estaria no nexo da diferença entre adaptação e adoção, a integração da contingência à evolução biológica e tecnológica. Viventes do reino animal, por exemplo, essencialmente adaptam-se ao ecossistema, mesmo os que parecem adotálo, como os castores, arquétipos de engenheiros alogênicos. Já os humanos não apenas se adaptam, mas adotam o meio circundante, porque a liberdade de escolha se cumpre na autodeterminação. A contingência torna-se, assim, necessária para afirmar a liberdade de ação. Os ecomodernistas, no limite, creem que a solução para resolver o problema do Antropoceno é desenvolver recursos tecnológicos para modular o sistema Terra, mas isso na verdade configura um outro tipo de adaptação.

Dossiê 0 Pensamento Ecológico - https://revistaecopos.eco.ufrj.br/

ISSN 2175-8689 - v. 23, n. 2, 2020

DOI: 10.29146/eco-pos.v23i2.27578 
Essas ações podem perfeitamente ser substituídas por práticas que emergem em relações recíprocas de coprodução entre elementos naturais e artificiais. Desde Schelling já se vociferava sobre os perigos de forçar o destaque das figuras em relação ao fundo, imagem gestáltica dos objetos técnicos que se sobressaem do fundo original da natureza (Urgrund), resultando na predominância da vontade própria sobre a coletiva.

Hui discorre sobre o conceito embutido na palavra anglófona smart, presente em locuções compostas da moda, como em smart cities, um quase sinônimo de inteligência, como em inteligência artificial (IA). Na organicidade inorgânica da quarta revolução industrial, o sistema técnico é otimizado de acordo com a interoperabilidade dos dispositivos e o conjunto se totaliza na interobjetividade de órgãos técnicos e digitais. Será necessário o reexame da noção de inteligência com o advento de recentes linguagens de IA, como o GPT-3, da OpenAI, processador de linguagem natural com poder de generalização para diversas aplicações, como a escrita de textos literários (i.e. Sudowrite). Ao invés de rastrear um banco de imagens, como o faz o modelo GAN, ele é treinado com base em corpus linguístico, desenvolvendo o restante do conteúdo a partir de predições. Tal é, segundo Hui, a concepção temporal ausente em Stiegler e Husserl, a saber, a percepção artificial de padrões futuros, a antecipação manifestada pelas máquinas computacionais ou, como nomeia o filósofo chinês, a protensão terciária. Mas aqui nos perguntamos se de fato o modelo da OpenAI é a prova de viabilidade da chamada Inteligência Artificial Geral ou se estaríamos evidentemente iludidos por um dos epifenômenos da inteligência: o uso atento da correspondência de padrões. Em último caso, poderíamos afirmar que os textos produzidos pelo modelo põem em risco a questão da autoria e restituem um dos temas dos diálogos de Fedro, onde se aponta a possibilidade da prática da retórica tecnicamente persuasiva sem o conhecimento da verdade que a sustenta.

Assim se explica, ao ver de Hui, a noção de sistema, uma "idealidade autodependente, realizada por uma forma orgânica (recursiva e contingente) 
matematicamente fundamentada" (Hui, 2019, p. 284). Se a proposição de Kant contra o mecanicismo cartesiano foi desenvolver um tipo de filosofia organicista a partir do juízo reflexivo, nos dias atuais faz-se preciso repensá-la, porque o próprio mecanismo torna-se orgânico, ou seja, o inorgânico passa a organizar-se (ou a se autoprogramar) como um superorganismo, sem que tenhamos que louvar as conquistas da biologia sintética ou reacender a refutação à autonomia técnica, pois, como assinala a citação à Georges Bernanos no curta metragem La France contre les robots (Jean-Marie Straub, 2020), "o sistema não mudará o curso de sua evolução pela razão de que ele já não está mais evoluindo; está apenas organizado". Se a filosofia do organicismo tem algo de ameaçador no atual estágio tecnológico planetário, isso tem a ver com a noção implícita de totalidade, restando-nos porventura contrabalançá-la com uma reformulação do mecanicismo, de caráter fragmentário, mas sem esquecer de neutralizar o seu aspecto mais problemático, qual seja, o de explicar a vida artificial abstendo-se dos viventes, como bem observou Canguilhem (Hui, 2019, p. 208).

Hui retoma a noção de cosmotécnica - detalhada em seu segundo livro, The Question Concerning Technology in China: An Essay in Cosmotechnics (2016) -, a qual busca reposicionar a tecnologia além da concretização dos objetos técnicos, ou seja, dispõe-na sobre fundamentos metafísicos. É antes de tudo um movimento para "recosmicizar" (récosmiser, na palavra de Augustin Berque) o pensamento da técnica, secularizado desde os primórdios da modernidade tecnocientífica. Não é o caso de se recorrer ao essencialismo heideggeriano da "técnica como destino", e sim de reorientar a episteme, reenquadrar o senso que dá vazão à produção de conhecimentos em uma determinada época, reequilibrando a figura e o fundo, e reanexando técnica e natureza em projetos coexistenciais. Em termos morais, propõe uma poiesis técnica em conformidade com a ordem cósmica, como a faca do açougueiro que "conhece" as formas implícitas das carnes destrinchadas (Hui, 2017). A menção à episteme como senso do sensível, o qual pode ser tanto o objeto de arte estruturado pelo saber técnico como o ato comum daquele que sente e do que é

Dossiê 0 Pensamento Ecológico - https://revistaecopos.eco.ufrj.br/

ISSN 2175-8689 - v. 23, n. 2, 2020

DOI: 10.29146/eco-pos.v23i2.27578 
sentido (Dufrenne, 2015, p. 82), eleva-a sobre a epistemologia e nos exorta sobre a necessidade de uma educação sensorial e estética. Suponhamos que seria possível então compreender a cosmotécnica como mais do que uma filosofia do pluralismo técnico, mas como uma legítima mediação entre técnicas e religiões, mais fértil que a estética proposta por Simondon, já que carrega dentro de si um embrião filosófico.

O quinto e último capítulo é crucial. Tendo ponderado sobre o modo de pensamento orgânico por meio da contingência e recursão, Hui formula a hipótese sobre como a noção de inumano (na acepção que lhe conferiu Jean-François Lyotard) configura uma resposta ao ocaso da filosofia que vem se desdobrando desde Kant até a cibernética. Tal ocaso passa pela antinomia entre as leis da natureza - que, não esqueçamos, têm como "objetivo" a paz global inscrita na história - e a liberdade humana, hoje reconfigurada na célebre frase de Thomas Jefferson "o preço da liberdade é a eterna vigilância", e segue com a crítica pós-modernista de Lyotard, que resume a produção de conhecimento por meio de desenvolvimento tecnológico na palavra "sistema", organismo infenso a representações. Essa lacuna, ou ponto cego, tem um quê de sublime, o "absoluto da percepção" (Dufrenne, 2015, p. 68). Mais ainda, tem um quê de inumano. Aqui faz-se necessário refletir mais detidamente sobre o inumano expresso no projeto lyotardiano, porque é a partir dele que Hui constrói uma legítima crítica ao humanismo. É, antes de tudo, uma crítica ao humanismo radical do transumanismo, releitura do cartesianismo disfarçado de organologia negativa que projeta recipientes não-orgânicos para a mente humana, tendo em conta a garantia de destruição do planeta com a morte do sol daqui a 5 bilhões de anos. Ao se contrapor ao transumanismo, o inumano se contrapõe ao humano, mas, simultaneamente, se predispõe a um tipo de póshumanismo ambivalente: contesta o humanismo antropocêntrico forjado ao longo da modernidade e, por seu caráter incognoscível, atua como fator de resistência à sistematização calculista do sistema técnico. 0 segundo ponto é importante, porque aposta no impensável como antídoto ao correlacionismo, visão que dá como acesso único ao conhecimento a via que interliga pensamento e ser. É decerto uma visão

Dossiê 0 Pensamento Ecológico - https://revistaecopos.eco.ufrj.br/

ISSN 2175-8689 - v. 23, n. 2, 2020

DOI: 10.29146/eco-pos.v23i2.27578 
não reducionista, pela arte e pela vida, como se fosse neovitalista, onde a informação, em sua versão diferencial e contingente, faz-se imensurável.

A organologia de Hui - a sua cosmotécnica - é um gesto consistente de combate à alienação contemporânea em um contexto onde a tecnologia computacional ameaça monopolizar a produção de conhecimento, substituindo a laboriosa produção teórica por correlações de arquivos em diferentes bases de dados (Anderson, 2008). É neovitalista ao qualificar a inteligência como intuitiva e contingente, para retomar a imagem de Goethe, segundo a qual "pensar nunca ajuda a pensar; temos de acertar naturalmente, de modo que as boas ideias sempre se apresentem a nós como livres filhas de Deus e nos interpelem dizendo: aqui estamos!" (Eckermann, 2018, p. 97). Essa abertura da tecnocultura às contingências, Hui observa, é o caminho que conduz à tecnodiversidade - complemento do multinaturalismo e outras ontologias antropológicas que superam a descontinuidade entre corpos orgânicos, não orgânicos e inorgânicos, o último sendo sinônimo do inumano instrumental (na acepção do filósofo australiano McKenzie Wark) - e à noodiversidade - pluralidade de modos de conhecimento e sensibilidades subjacentes a esses modos de saber. Bem como é neo-organicista ao reestabelecer, contra o mecanicismo determinista da automação repetitiva, o pluralismo de modelos computacionais recursivos com amplas margens de indeterminação e que inserem os humanos dentro do circuito (human-in-the-loop). Se busca reterritorializar a episteme, com a ideia de "polilocalidade" (localismo cosmopolítico não-substancialista e não-tradicionalista), é porque trata-se de um programa antes de tudo estético (a base da episteme, segundo Hui), razão pela qual (cremos) o próximo livro do autor intitula-se Art and Cosmotechnics.

\section{Referências bibliográficas}

ANDERSON, Chris. The End of Theory: The Data Deluge Makes the Scientific Method Obsolete. Wired, 23 jun. 2008. Disponível em: <https://www.wired.com/2008/06/pbtheory/>. Acesso em: 6 ago. 2020.

Dossiê 0 Pensamento Ecológico - https://revistaecopos.eco.ufrj.br/

ISSN $2175-8689$ - v. 23, n. 2, 2020

DOI: 10.29146/eco-pos.v23i2.27578 
AUGSTEIN, Rudolf; WOLFF, Georg. Only a God Can Save Us. Der Spiegel, 31 mai. 1976.

BURNHAM, Jack. Beyond Modern Sculpture: The Effects of Science and Technology on the Sculpture of this Century. Nova Iorque: G. Braziller, 1968.

DUFRENNE, Mikel. Estética e Filosofia. São Paulo: Perspectiva, 2015.

ECKERMANN, Johann Peter. Conversações com Goethe nos últimos anos de sua vida (18231832). São Paulo: Editora UNESP, 2018.

HUI, Yuk. Recursivity and Contingency. Nova Iorque: Rowman \& Littlefield International, Limited, 2019.

HUI, Yuk. Cosmotechnics as Cosmopolitics. e-flux, n. 86, Nov. 2017. Disponível em: <https://www.e-flux.com/journal/86/161887/cosmotechnics-as-cosmopolitics/>. Acesso em: 4 ago. 2020.

LENOIR, Timothy. The Strategy of Life: Teleology and Mechanics in Nineteenth-Century German Biology. Dordrecht, Holanda: D. Reidel Publishing Company, 1982.

LOVINK, Geert. Cybernetics for the Twenty-First Century: An Interview with Philosopher Yuk Hui. e-flux, n. 102, Set. 2019. Disponível em: <https://www.eflux.com/journal/102/282271/cybernetics-for-the-twenty-first-century-an-interviewwith-philosopher-yuk-hui/>. Acesso em: 5 ago. 2020. 